Pacific Journal of Mathematics

A SUBFUNCTION APPROACH TO A BOUNDARY VALUE
PROBLEM FOR ORDINARY DIFFERENTIAL EQUATIONS 


\title{
A SUBFUNCTION APPROACH TO A BOUNDARY VALUE PROBLEM FOR ORDINARY DIFFERENTIAL EQUATIONS
}

\author{
J. W. BeBERNES
}

1. Introduction. Consider the ordinary, second-order differential equation

$$
y^{\prime \prime}=f\left(x, y, y^{\prime}\right)
$$

where $f\left(x, y, y^{\prime}\right)$ is a real-valued function defined on the region

$$
T=\left\{\left(x, y, y^{\prime}\right)|a \leqq x \leqq b,| y|<\infty,| y^{\prime} \mid<\infty\right\},
$$

$a$ and $b$ finite.

The purpose of this paper is to determine sufficient conditions which when placed on $f\left(x, y, y^{\prime}\right)$ guarantee the existence of a unique solution of the two-point boundary value problem (BVP):

$$
y^{\prime \prime}=f\left(x, y, y^{\prime}\right), \quad y(a)=\alpha, \quad y(b)=\beta .
$$

A solution of the BVP: $y^{\prime \prime}=f\left(x, y, y^{\prime}\right), y\left(x_{1}\right)=y_{1}, y\left(x_{2}\right)=y_{2}$, where $a \leqq x_{1} \leqq x_{2} \leqq b$ will be defined to be a function $y(x)$ which is of class $C^{2}$ and satisfies (1.1) on $\left(x_{1}, x_{2}\right)$, which is continuous on $\left[x_{1}, x_{2}\right]$, and which assumes the given boundary values at $x_{1}$ and $x_{2}$.

The following assumptions will be placed on $f\left(x, y, y^{\prime}\right)$ as needed.

$\left(\mathrm{A}_{0}\right) \quad f\left(x, y, y^{\prime}\right)$ is continuous on $T$.

$\left(\mathrm{A}_{1}\right) f\left(x, y, y^{\prime}\right)$ is a non-decreasing function of $y$ for each fixed $x$ and $y^{\prime}$ in $T$.

$\left(\mathrm{A}_{2}\right) f\left(x, y, y^{\prime}\right)$ satisfies a Lipschitz condition with respect to $y^{\prime}$ on each fixed compact subset to $T$.

The primary results of this paper are the following two theorems.

THEOREM 6.2. If

(1) $f\left(x, y, y^{\prime}\right)$ satisfies $\mathrm{A}_{0}, \mathrm{~A}_{1}$, and $\mathrm{A}_{2}$,

(2) there exists a positive continuous function $\phi(u)$ defined for $u \geqq 0$ such that

$$
\left|f\left(x, y, y^{\prime}\right)-f(x, y, 0)\right| \leqq K_{s} \phi\left(\left|y^{\prime}\right|\right)
$$

where $K_{s}$ is a constant depending on compact subsets $S$ of

$$
\{(x, y)|a \leqq y \leqq b,| y \mid<\infty\}, \quad(x, y) \in S, \quad\left|y^{\prime}\right|<\infty,
$$

Received Feburary 13, 1963. Research was in part supported by the United States Air Force through the Air Force Office of Scientific Research of the Air Research and Development Command. This paper is a portion of a doctoral thesis written under the supervision of Professor Lloyd K. Jackson at the University of Nebraska. 
and

$$
\int_{0}^{\infty} \frac{u d u}{\phi(u)+1}=\infty
$$

(3) $\left|f\left(x, 0, y^{\prime}\right)-f(x, 0,0)\right| \leqq K\left|y^{\prime}\right|$ for $a \leqq x \leqq b$ and $\left|y^{\prime}\right|<\infty$, then there exists a unique solution of the BVP (1.2) of class $C^{2}[a, b]$.

THEOREM 6.3. If given the BVP: $y^{\prime \prime}=f\left(x, y, y^{\prime}\right), y(a)=0=y(b)$, with

(1) $f\left(x, y, y^{\prime}\right)$ satisfying $\mathrm{A}_{0}, \mathrm{~A}_{1}, \mathrm{~A}_{2}$, and

(2) $\left|f\left(x, 0, y^{\prime}\right)-f(x, 0,0)\right| \leqq K\left|y^{\prime}\right|$ for all $a \leqq x \leqq b$ and $\left|y^{\prime}\right|<+\infty$, then there exists a unique solution of the BVP of class $C^{2}[a, b]$.

Lees [4] proved that if $f\left(x, y, y^{\prime}\right)$ satisfies $A_{0}, A_{1}$, and, in place of $\mathrm{A}_{2}$, a uniform Lipschitz condition with respect to $y^{\prime}$, then there exists a unique solution of the BVP (1.2) of class $C^{2}[a, b]$. Note that Lees' result is immediate from Theorem 6-2. Whereas Lees used the method of finite differences, we shall attack the BVP (1.2) employing the theory of subfunctions developed by Fountain and Jackson [3]. In [3], Fountain and Jackson utilized the theory of subfunctions to construct a so-called generalized solution of the BVP (1.2) in the sense that if a solution exists it will be this generalized solution by uniqueness. To construct this generalized solution, they assumed $f\left(x, y, y^{\prime}\right)$ satisfies $\mathrm{A}_{0}, \mathrm{~A}_{1}$, and, in place of $\mathrm{A}_{2}$, that:

$\left(\mathrm{A}_{2}^{\prime}\right) \quad f\left(x, y, y^{\prime}\right)$ satisfies a Lipschitz condition with respect to $y$ and $y^{\prime}$ on each fixed compact subset of $T$.

In this paper, we shall construct the generalized solution of the BVP (1.2) as in [3] under assumptions $A_{0}, A_{1}$ and $A_{2}$. Most of the proofs carry over with only slight modifications. By knowing properties of this generalized solution, additional conditions can then be imposed on $f\left(x, y, y^{\prime}\right)$ to assure a solution of the BVP (1.2).

2. A "local" existence theorem and a maximum principle. The two theorems in this section form the basis for the construction of the generalized solution of the BVP (1.2). The "local" existence theorem is known and was first proven by E. Picard [6, pp. 9-36] in a slightly weaker form.

THEOREM 2.1. Let $f\left(x, y, y^{\prime}\right)$ satisfy $\mathrm{A}_{0}$, then given $M, N>0$ there is a $\delta(M, N)>0$ such that the BVP:

$$
y^{\prime \prime}=f\left(x, y, y^{\prime}\right), \quad y\left(x_{1}\right)=y_{1}, \quad y\left(x_{2}\right)=y_{2}
$$

has a solution of class $C^{2}$ on $\left[x_{1}, x_{2}\right]$ for any points $\left(x_{1}, y_{1}\right)$ and $\left(x_{2}, y_{2}\right)$ with $x_{1}, x_{2} \in[a, b], \quad\left|x_{1}-x_{2}\right| \leqq \delta,\left|y_{1}\right| \leqq M,\left|y_{2}\right| \leqq M$, and $\left|\left(y_{1}-y_{2}\right) /\left(x_{1}-x_{2}\right)\right| \leqq N$. 
The details of the proof of this result will not be given. Note that the BVP (2.1) has a solution if and only if the BVP:

$$
\begin{aligned}
& y^{\prime \prime}=f\left(x, z(x)+p x+q, z^{\prime}(x)+p\right) \\
& z\left(x_{1}\right)=0 \quad z\left(x_{2}\right)=0
\end{aligned}
$$

has a solution, and that the BVP (2.2) has a solution if there is a function $z(x) \in C^{\prime}\left[x_{1}, x_{2}\right]$ which is a solution of

$$
z(x)=\int_{x_{1}}^{x_{2}} G(x, s) f\left(s, z(s)+p s+q, z^{\prime}(s)+p\right) d s
$$

where

$$
G(x, s)=\left\{\begin{array}{ll}
\left(x_{1}-s\right)\left(x_{2}-x\right)\left(x_{2}-x_{1}\right)^{-1}, & x_{1} \leqq s \leqq x \\
\left(x_{1}-x\right)\left(x_{2}-s\right)\left(x_{2}-x_{1}\right)^{-1}, & x \leqq s \leqq x_{2}
\end{array} .\right.
$$

The Schauder-Tychonoff fixed-point theorem [2, p. 456] can be employed to show the existence of a solution of (2.3) of class $C^{\prime}$ on $\left[x_{1}, x_{2}\right]$.

The following corollary follows as an immediate consequence of the proof of Theorem 2.1.

Corollary 2.1. Let $M>0, N>0$ be fixed and let $\delta(M, N)>0$ be as in Theorem 2.1. Then given any $\varepsilon>0$ and any $\delta_{1}, 0<\delta_{1} \leqq$ $\delta(M, N)$, there is an $\eta, 0<\eta \leqq \delta_{1}$, such that for any points $\left(x_{1}, y_{1}\right)$ and $\left(x_{2}, y_{2}\right)$ with $x_{1}, x_{2} \in[a, b],\left|x_{1}-x_{2}\right| \leqq \eta,\left|y_{1}\right| \leqq M,\left|y_{2}\right| \leqq M$, and $\left|\left(y_{1}-y_{2}\right)\left(x_{1}-x_{2}\right)^{-1}\right| \leqq N$, there is a solution $y(x)$ of the BVP (2.1) on $\left[x_{1}, x_{2}\right]$ such that $|y(x)-w(x)| \leqq \varepsilon$ and $\left|y^{\prime}(x)-w^{\prime}(x)\right| \leqq \varepsilon$ where $w(x)$ is the linear function with $w\left(x_{1}\right)=y_{1}$ and $w\left(x_{2}\right)=y_{2}$.

For any function $g$ defined on $\left[x_{1}, x_{2}\right]$ and $x_{0} \in\left(x_{1}, x_{2}\right)$, define $\bar{D} g\left(x_{0}\right)=\lim \sup \left[g\left(x_{0}+\delta\right)-g\left(x_{0}-\delta\right)\right] / 2 \delta$ as $\delta \rightarrow 0$ and $\underline{D} g\left(x_{0}\right)=$ $\lim \inf \left[g\left(x_{0}+\delta\right)-g\left(x_{0}-\delta\right)\right] / 2 \delta$ as $\delta \rightarrow 0$.

LEMMA 2.1. If $f\left(x, y, y^{\prime}\right)$ satisfies $\mathrm{A}_{0}$ and $\mathrm{A}_{1}$ and if the functions $\phi(x)$ and $\psi(x)$ satisfy:

(i) $\phi, \psi \in C[c, d] \cap C^{\prime}(c, d)$ for $[c, d] \subset[a, b]$,

(ii) $\underline{D} \phi^{\prime}(x) \geqq f\left(x, \phi(x), \phi^{\prime}(x)\right)$ and $\bar{D} \psi^{\prime}(x) \leqq f\left(x, \psi(x), \psi^{\prime}(x)\right)$ on $(c, d)$ with at least one of these being strict inequality on $(c, d)$, and

(iii) $\phi(c)-\psi(c) \leqq M$ and $\phi(d)-\psi(d) \leqq M$ where $M \geqq 0$, then

$$
\varphi(x)-\psi(x)<M \text { on }(c, d) .
$$

Observe that it suffices to consider only the case $M=0$. If we assume the conclusion is false, we have an almost immediate contradiction. 
Lemma 2.2. If $f\left(x, y, y^{\prime}\right)$ satisfies $\mathrm{A}_{0}, \mathrm{~A}_{1}$, and $\mathrm{A}_{2}$, and if there is a function $\phi$ such that:

(i) $\phi \in C^{\prime}\left[x_{1}, x_{2}\right]$ where $\left[x_{1}, x_{2}\right] \subset[a, b]$,

(ii) $\underline{D} \phi^{\prime}(x) \geqq f\left(x, \phi(x), \phi^{\prime}(x)\right)$ on $\left(x_{1}, x_{2}\right)$, then given $\varepsilon>0$ there is a function $\phi_{1} \in C^{\prime}\left[x_{1}, x_{2}\right]$ such that $\phi(x)-\varepsilon \leqq$ $\phi_{1}(x) \leqq \phi(x)$ on $\left[x_{1}, x_{2}\right]$ and

$$
\underline{D} \phi_{1}^{\prime}(x)>f\left(x, \phi_{1}(x), \phi_{1}^{\prime}(x)\right) \quad \text { on }\left(x_{1}, x_{2}\right) \text {. }
$$

Proof. Let $|\phi(x)|+\left|\phi^{\prime}(x)\right| \leqq R$ on $\left[x_{1}, x_{2}\right]$ and let

$$
T^{*}=\left\{\left(x, y, y^{\prime}\right)\left|x_{1} \leqq x \leqq x_{2},\right| y|\leqq R+1,| y^{\prime} \mid \leqq R+1\right\} .
$$

Let $K>0$ be such that $\left|f\left(x, y, y_{1}^{\prime}\right)-f\left(x, y, y_{2}^{\prime}\right)\right| \leqq K\left|y_{1}^{\prime}-y_{2}^{\prime}\right|$ for all $\left(x, y, y_{1}^{\prime}\right),\left(x, y, y_{2}^{\prime}\right) \in T^{*}$. Let $z(x)$ be a solution of $z^{\prime \prime}=(K+1) z^{\prime}$ on $\left[x_{1}, x_{2}\right]$ which satisfies the conditions $0 \leqq z(x) \leqq \varepsilon$ and $-1 \leqq z^{\prime}(x)<0$ on $\left[x_{1}, x_{2}\right]$. Then on $\left(x_{1}, x_{2}\right)$

$$
\begin{aligned}
& \underline{D}\left[\phi^{\prime}(x)-z^{\prime}(x)\right]-f\left(x, \phi(x)-z(x), \phi^{\prime}(x)-z^{\prime}(x)\right) \\
& \quad \geqq f\left(x, \phi(x), \phi^{\prime}(x)\right)-f\left(x, \phi(x), \phi^{\prime}(x)-z^{\prime}(x)\right)-z^{\prime \prime}(x) \\
& \quad \geqq-K\left|z^{\prime}(x)\right|-(K+1) z^{\prime}(x) \\
& \quad=-z^{\prime}(x)>0 .
\end{aligned}
$$

Hence, $\phi_{1}(x) \equiv x(\phi)-z(x)$ is the desired function.

A dual statement holds by reversing the inequalities. We shall refer to the dual of a result by using an asterisk (for example, Lemma 2.2*).

Theorem 2.2 (Maximum Principle). If $f\left(x, y, y^{\prime}\right)$ satisfies $\mathrm{A}_{0}, \mathrm{~A}_{1}$, and $\mathrm{A}_{2}$, and if there exist functions $\phi$ and $\psi$ satisfying:

(i) $\phi, \psi \in C^{\prime}(c, d) \cap C[c, d]$ for some $[c, d] \subset[a, b]$,

(ii) $\underline{D} \phi^{\prime}(x) \geqq f\left(x, \phi(x), \phi^{\prime}(x)\right)$ and $\bar{D} \psi^{\prime}(x) \leqq f\left(x, \psi(x), \psi^{\prime}(x)\right)$ on $(c, d)$,

(iii) $\phi(c)-\psi(c) \leqq M$ and $\phi(d)-\psi(d) \leqq M$ for some $M \geqq 0$, then $\phi(x)-\psi(x) \leqq M$ on $[c, d]$.

Proof. It suffices to consider only the case where $M=0$. Let $M=0$ and assume conclusion is false. Then there exist $x \in(c, d)$ such that $\phi(x)-\psi(x)>0$. Let $N=\max [\phi(x)-\psi(x)]>0, x \in[c, d]$, and let $x_{0} \in(c, d)$ be such that $\phi\left(x_{0}\right)-\psi\left(x_{0}\right)=N$. There exist $x_{1}, x_{2} \in(c, d)$ such that $\phi\left(x_{1}\right)-\psi\left(x_{1}\right) \leqq N / 2, \phi\left(x_{2}\right)-\psi\left(x_{2}\right) \leqq N / 2$ and $x_{1}<x_{0}<x_{2}$. Choose $\varepsilon$ such that $0<\varepsilon \leqq N / 2$. By Lemma 2.2*, there exists a function $\psi_{1}(x) \in C^{\prime}\left[x_{1}, x_{2}\right]$ with

$$
\psi(x) \leqq \psi_{1}(x) \leqq \psi(x)+\varepsilon \text { and } \bar{D} \psi_{1}^{\prime}(x)<f\left(x, \psi_{1}(x), \psi_{1}^{\prime}(x)\right) \text { on }\left(x_{1}, x_{2}\right) \text {. }
$$

Then $\phi(x)-\psi_{1}(x)<N / 2$ on $\left(x_{1}, x_{2}\right)$ by Lemma 2.1. In particular, $\phi\left(x_{0}\right)-\psi_{1}\left(x_{0}\right)<N / 2$ so 


$$
\phi\left(x_{0}\right)<\psi_{1}\left(x_{0}\right)+N / 2 \leqq \psi\left(x_{0}\right)+\varepsilon+N / 2 \leqq \psi\left(x_{0}\right)+N
$$

which is a contradiction.

Uniqueness of solutions of the BVP is immediate from the Maximum Principle.

Corollary 2.2. Let $f\left(x, y, y^{\prime}\right)$ satisfy $\mathrm{A}_{0}, \mathrm{~A}_{1}$, and $\mathrm{A}_{2}$. Then the solution of the BVP: $y^{\prime \prime}=f\left(x, y, y^{\prime}\right), y\left(x_{1}\right)=y_{1}, y\left(x_{2}\right)=y_{2}$, for $\left[x_{1}, x_{2}\right] \subset[a, b]$, if it exists, is unique.

The following example shows that the Maximum Principle does not remain valid if we replaced $\mathrm{A}_{2}$ by the following weaker assumption:

$\left(\mathrm{A}_{2}^{*}\right) f\left(x, y, y^{\prime}\right)$ satisfies a Hölder condition with exponent $\alpha$, $0<\alpha<1$, with respect to $y^{\prime}$ on each fixed compact subset of $T$. Consider the BVP: $y^{\prime \prime}=f\left(x, y, y^{\prime}\right)=A^{1-\alpha}|a|^{p(\alpha-1)} p^{1-\alpha}(p-1)\left|y^{\prime}\right|^{\alpha}$ with $y(-a)=y(a)=A>0 \quad$ where $\quad \alpha=(p-2)(p-1)^{-1}, p>2 . \quad f\left(x, y, y^{\prime}\right)$ satisfies $\mathrm{A}_{0}, \mathrm{~A}_{1}$, and $\mathrm{A}_{2}^{*}$, but $y_{1}(x)=A$ and $y_{2}(x)=A|a|^{-p}|x|^{p}$ are distinct solutions of the BVP.

3. Subfunctions. The concept of sub- and superfunctions and their properties are fundamental for the remainder of this paper. For this reason some of the known results for subfunctions due to Fountain and Jackson [3] will be stated without proof. In [3] these results were proven assuming $f\left(x, y, y^{\prime}\right)$ satisfies $\mathrm{A}_{0}, \mathrm{~A}_{1}$, and $\mathrm{A}_{2}^{\prime}$. If $f\left(x, y, y^{\prime}\right)$ satisfies $\mathrm{A}_{0}, \mathrm{~A}_{1}$, and $\mathrm{A}_{2}$, the proofs can be carried through as in [3] with only slight modifications.

Throughout this section, we shall assume that $f\left(x, y, y^{\prime}\right)$ satisfies $\mathrm{A}_{0}$ although no further explicit mention of this fact will be made. $I$ will denote an interval of $[a, b], \operatorname{cl}(I)$ the closure of $I$, and $I^{\circ}$ the interior of $I$.

Definition 3.1. A real-valued function $s$ defined on $I$ is said to be subfunction on $I$ in case $s(x) \leqq y(x)$ on $\left[x_{1}, x_{2}\right]$ for any $\left[x_{1}, x_{2}\right] \subset I$ and any solution $y$ of $(1.1)$ on $\left[x_{1}, x_{2}\right]$ with $s\left(x_{1}\right) \leqq y\left(x_{1}\right)$ and $s\left(x_{2}\right) \leqq y\left(x_{2}\right)$.

Superfunctions are defined dually by reversing inequalities in the preceding definition, and dual results hold.

Subfunctions satisfy the following properties.

(3.1). If $s(x)$ is a subfunction on $I$, then the right- and left-hand limits exist in the extended reals with appropriate limits existing at the endpoints of $c l(I), s\left(x_{0}\right) \leqq \max \left[s\left(x_{0}-0\right), s\left(x_{0}+0\right)\right]$ for $x_{0} \in I^{\circ}$, and the number of discontinuities of $s(x)$ on $I$ is at most countable.

(3.2). If $s(x)$ is a bounded subfunction on $I$ with $\operatorname{cl}(I)$ having 
endpoints $x_{1}$ and $x_{2}$, then, if

$$
d^{+} s\left(x_{0}\right)=\lim \sup \left[s(x)-s\left(x_{0}+0\right)\right] /\left(x-x_{0}\right)
$$

and

$$
d_{+} s\left(x_{0}\right)=\liminf \left[s(x)-s\left(x_{0}+0\right)\right] /\left(x-x_{0}\right) \quad \text { as } x \rightarrow x_{0}^{+}
$$

with $d^{-} s\left(x_{0}\right)$ and $d_{-} s\left(x_{0}\right)$ analogously defined, $d^{-} s\left(x_{0}\right)=d_{-} s\left(x_{0}\right)$ for all $x_{1}<x_{0} \leqq x_{2}$ and $d^{+} s\left(x_{0}\right)=d_{+} s\left(x_{0}\right)$ for all $x_{1} \leqq x_{0}<x_{2}$ and, hence, $s(x)$ has a finite derivative almost everywhere on $I$.

(3.3). The supremum of a collection of subfunctions bounded above at each point of $I$ is a subfunction on $I$.

(3.4). If $s(x)$ is a subfunction of class $C^{\prime}$ on $I$, then $\underline{D} s^{\prime}(x) \geqq$ $f\left(x, s(x), s^{\prime}(x)\right)$ on $I^{\circ}$.

(3.5). If $f\left(x, y, y^{\prime}\right)$ satisfies $\mathrm{A}_{1}$ and $\mathrm{A}_{2}$, if $s(x) \in \operatorname{cl}(I) \cap C^{\prime}\left(I^{\circ}\right)$, and if $\underline{D} s^{\prime}(x) \geqq f\left(x, s(x), s^{\prime}(x)\right)$ on $I^{\circ}$, then $s(x)$ is a subfunction on $I$.

(3.6). Let $s_{1}$ be a subfunction on $I$ and $s_{2}$ a subfunction on $\left[x_{1}, x_{2}\right] \subset \operatorname{cl}(I)$. Assume further that $s_{2}\left(x_{i}\right) \leqq s_{1}\left(x_{i}\right), i=1,2$, in case $x_{i} \in I^{\circ}$. Then

$$
s(x)=\left\{\begin{array}{l}
s_{1}(x), \quad x \notin\left[x_{1}, x_{2}\right] \\
\max \left[s_{1}(x), s_{2}(x)\right], \quad x \in\left[x_{1}, x_{2}\right]
\end{array}\right.
$$

is a subfunction on $I$.

(3.7). If $f\left(x, y, y^{\prime}\right)$ satisfies $\mathrm{A}_{1}$ and $\mathrm{A}_{2}$, if $s(x)$ and $S(x)$ are continuous sub- and superfunctions on $c l(I)$, if one of $s(x)$ and $S(x)$ is of class $C^{\prime}$ on $I^{\circ}$, and if $s\left(x_{i}\right) \leqq S\left(x_{i}\right), i=1,2$, where $x_{i}$ are the endpoints of $I$, then $s(x) \leqq S(x)$ on $\operatorname{cl}(I)$.

(3.8). If $f\left(x, y, y^{\prime}\right)$ satisfies $\mathrm{A}_{1}$ and $\mathrm{A}_{2}$ and if $s(x)$ is a continuous subfunction on $I$, then $s(x)-M$ is a continuous subfunction on $I$ where $M$ is an arbitrary nonnegative constant.

4. A generalized solution of the boundary value problem. A function $H(x)$ will be defined which will be referred to as the "generalized solution" of the BVP in the sense that if a solution of the BVP exists and if $f\left(x, y, y^{\prime}\right)$ satisfies certain to-be-determined conditions, then $H(x)$ is that solution.

Definition 4.1. A function $\phi(x)$ is said to be an underfunction 
with respect to the BVP (1.2) in case $\phi(x)$ is a subfunction on $[a, b]$ with $\phi(a) \leqq \alpha$ and $\phi(b) \leqq \beta$.

Overfunctions are defined dually. For the construction of the "generalized solution," the following assumptions will be needed. Assume

$\left(\mathrm{A}_{3}\right) f\left(x, y, y^{\prime}\right)$ is such that with respect to the given BVP there is an underfunction which is continuous on $[a, b]$ and there is an overfunction which is continuous on $[a, b]$ and of class $C^{\prime}$ on $(a, b)$.

Definition 4.2. Let $\{\phi\}$ be the family of all underfunctions with respect to the BVP (1.2) which are continuous on $[a, b]$. Define

$$
H(x)=\sup [\phi(x) \mid \phi \in\{\phi\}]
$$

for each $x \in[a, b] . \quad H(x)$ is called the generalized solution of the BVP. $H(x)$ satisfies the following properties the proofs of which are given in [3], assuming $f\left(x, y, y^{\prime}\right)$ satisfies $\mathrm{A}_{0}, \mathrm{~A}_{1}, \mathrm{~A}_{2}^{\prime}$, and $\mathrm{A}_{3}$. If $f\left(x, y, y^{\prime}\right)$ satisfies $\mathrm{A}_{0}, \mathrm{~A}_{1}, \mathrm{~A}_{2}$, and $\mathrm{A}_{3}$, the proofs of these results carry through with some modification. Assuming that $f\left(x, y, y^{\prime}\right)$ satisfies $\mathrm{A}_{0}, \mathrm{~A}_{1}, \mathrm{~A}_{2}$, and $\mathrm{A}_{3}$, then:

(4.1). $H(x)$ is both a bounded sub- and superfunction on $[a, b]$ with $H(x)=\min [H(x+0), H(x-0)], x \in(a, b)$.

(4.2). $H(x)$ is a solution of $y^{\prime \prime}=f\left(x, y, y^{\prime}\right)$ on an open subset of $[a, b]$, the complement of which is of measure 0 .

(4.3). $D H\left(x_{0}-0\right)=D H\left(x_{0}+0\right)$ on $(a, b)$ where

$$
D H\left(x_{0} \pm 0\right)=\lim \left[H(x)-H\left(x_{0} \pm 0\right)\right] /\left(x-x_{0}\right) \text { as } x-x_{0}^{ \pm} .
$$

More specifically, let $E$ be the set of interior points of $[a, b]$ at which $H(x)$ does not have a finite derivative, then (i) if $H(x+0)>H(x-0)$, $D H(x+0)=D H(x-0)=+\infty$, (ii) if $H(x+0)<H(x-0), D H(x+0)=$ $D H(x-0)=-\infty$; (iii) if $x \in E$ is a point of discontinuity, $D H(x+0)=$ $D H(x-0)= \pm \infty$.

(4.4) (i) if $D H(b-0) \neq-\infty, H(b-0)=H(b)$, (ii) if $H(b-0)<\beta$, $D H(b-0)=+\infty$, and (iii) if $D H(b-0)$ is finite, $H(b-0)=H(b)=$ $\beta$. Similar results hold at $x=a$.

Consider the BVP: $y^{\prime \prime}=f\left(x, y, y^{\prime}\right)=-18 x\left(y^{\prime}\right)^{4}$ with $y(-1)=-1$ and $y(1)=1 . \quad f\left(x, y, y^{\prime}\right)$ satisfies $\mathrm{A}_{0}, \mathrm{~A}_{1}, \mathrm{~A}_{2}$, and $\mathrm{A}_{3}$. However, no solution of this BVP exists for if it did the solution would be $y_{0}(x)=$ $x^{1 / 3}$. It can be shown that $H(x)=y_{0}(x)$ on $[-1,1]$. Although the 
generalized solution exists, this example points out the fact that more stringent conditions must be imposed on $f\left(x, y, y^{\prime}\right)$ to guarantee that a solution of the BVP exists.

Definition 4.3. A differential equation $y^{\prime \prime}=f\left(x, y, y^{\prime}\right)$ is said to satisfy property $(\mathrm{P})$ in case given any $A>0$ and any compact subset $S \subset\{(x, y)|a \leqq x \leqq b| y \mid,<\infty\}$, there exists $B_{(A S)}>0$ such that for any solution $y(x)$ of $y^{\prime \prime}=f\left(x, y, y^{\prime}\right)$ with the initial condition $y\left(x_{0}\right)=y_{0}$ and $\left|y^{\prime}\left(x_{0}\right)\right| \leqq A$ where $\left(x_{0}, y_{0}\right) \in S$ the inequality $\left|y^{\prime}(x)\right|<B_{(A, S)}$ holds as long as $(x, y(x)) \in S$.

THEOREM 4.1. Let $f\left(x, y, y^{\prime}\right)$ satisfy $A_{i}, i=0, \cdots, 3$, and let (1.1) satisfy property (P), then $H(x)$ is a solution of the BVP (1.2) of class $C^{2}$ on $[a, b]$.

The proof follows from (4.2), (4.3), and (4.4).

5. "Natural" conditions for $f(x, y, y$ '). By Theorem 4.1, a solution of the BVP (1.2) exists provided assumptions $A_{i}, i=0, \cdots, 3$, and property $(\mathrm{P})$ are satisfied. Of these, assumption $\mathrm{A}_{3}$ and property (P) are unnatural in the sense that they are not imposed directly on $f\left(x, y, y^{\prime}\right)$. "Natural" conditions will be given in this section which imply $\mathrm{A}_{3}$ and $\mathrm{P}$.

Sufficient conditions to assure that $y^{\prime \prime}=f\left(x, y, y^{\prime}\right)$ satisfies property (P) are given in the following theorem which is similar to a result due to Nagumo [5, pp. 861-863].

THEOREM 5.1. Let

(1) $f\left(x, y, y^{\prime}\right)$ satisfy $\mathrm{A}_{0}$

(2) $\phi(u)$ be a positive continuous function of $u(u \geqq 0)$ such that

$$
\left|f\left(x, y, y^{\prime}\right)-f(x, y, 0)\right| \leqq K_{s} \phi\left(\left|y^{\prime}\right|\right)
$$

where $K_{S}$ is a constant depending on compact subsets

$$
S \subset\{(x, y)|a \leqq x \leqq b,| y \mid<\infty\}, \quad(x, y) \in S, \quad\left|y^{\prime}\right|<\infty,
$$

and

$$
\int_{0}^{\infty} \frac{u d u}{\phi(u)+1}=+\infty
$$

then $y^{\prime \prime}=f\left(x, y, y^{\prime}\right)$ satisfies property $(\mathrm{P})$.

Proof. Let $S$ be any compact subset of $\{(x, y)|a \leqq x \leqq b| y \mid,<\infty\}$, then for any $\left(x_{1}, y_{1}\right),\left(x_{2}, y_{2}\right) \in S$ there is an $L>0$ such that $\left|y_{1}-y_{2}\right|<L$. 
By (5.2), given any $A>0$ there exists $B_{(A, S)}>A$ such that

$$
\int_{A}^{B_{(A, S)}} \frac{u d u}{\phi(u)+1}>L \cdot K
$$

where $K=\max \left[K_{S}, \max _{(x y) \in S}|f(x, y, 0)|\right]$.

Let $y(x)$ be an arbitrary solution of $y^{\prime \prime}=f\left(x, y, y^{\prime}\right)$ with initial conditions $y\left(x_{0}\right)=y_{0}, y^{\prime}\left(x_{0}\right)=A$ where $\left(x_{0}, y_{0}\right) \in S$. Let $x_{1} \leqq x \leqq x_{2}$ be an interval such that $(x, y(x)) \in S$ and $x_{1} \leqq x_{0} \leqq x_{2}$. Claim $y^{\prime}(x)<B_{(A S)}$ on $\left[x_{1}, x_{2}\right]$. If not, there would be two points $t_{1}$ and $t_{2}$ in $\left[x_{1}, x_{2}\right]$ such that $y^{\prime}\left(t_{1}\right)=A, y^{\prime}\left(t_{2}\right)=B_{(A S)}$, and $A \leqq y^{\prime}(x) \leqq B_{(A, S)}$ for $x \in\left[t_{1}, t_{2}\right]$ assuming without loss of generality that $t_{1}<t_{2}$.

By (5.1), $f\left(x, y, y^{\prime}\right) \leqq K\left(\phi\left(\left|y^{\prime}\right|\right)+1\right)$ and thus

$$
\frac{y^{\prime} y^{\prime \prime}}{\phi\left(\left|y^{\prime}\right|\right)+1} \leqq K y^{\prime} \text {. }
$$

Therefore,

$$
\int_{A}^{B_{(A, S)}} \frac{u d u}{\phi(u)+1}=\int_{t_{1}}^{t_{2}} \frac{y^{\prime} y^{\prime \prime} d x}{\phi\left(\left|y^{\prime}\right|\right)+1} \leqq K \int_{t_{1}}^{t_{2}} y^{\prime} d x \leqq K \cdot L
$$

which contradicts (5.3), and hence $y^{\prime}(x)<B_{(A, S)}$ on $\left[x_{1}, x_{2}\right]$. Analogously, one can show that $y^{\prime}(x)>-B_{(A S)}$ on $\left[x_{1}, x_{2}\right]$ whenever $y^{\prime}\left(x_{0}\right) \geqq-A$.

The following theorem imposes sufficient conditions which imply $A_{3}$ and, in fact, more.

THEOREM 5.2. Let $f\left(x, y, y^{\prime}\right)$ satisfy $A_{i}, i=0,1,2$, and

$$
\left|f\left(x, 0, y^{\prime}\right)-f(x, 0,0)\right| \leqq K\left|y^{\prime}\right|
$$

for all $a \leqq x \leqq b$ and $\left|y^{\prime}\right|<+\infty$, then there exists an overfunction $\psi(x)$ of class $C^{2}$ on $[a, b]$ and an underfunction $\phi(x)$ of class $C^{2}$ on $[a, b]$.

Proof. Let $R>0$ be such that $|f(x, 0,0)| \leqq R$ on $[a, b]$. Define

$$
\psi(x) \equiv \varepsilon_{1}\left(N-e^{m(x-a)}\right) \text { on }[a, b]
$$

where $m=K+1, \varepsilon_{1}=R m^{-1}+1$, and

$$
N=\max \left[\varepsilon_{1}^{-1} \cdot \alpha+1, \varepsilon_{1}^{-1} \beta+e^{m(b-a)}, e^{m(b-a)}\right] .
$$

Using (3.5), it is easily verified that $\psi(x)$ is an overfunction of class $C^{2}[a, b]$.

Similarly, $\phi(x)=\varepsilon_{2}\left(N-e^{m(x-a)}\right)$ where $\varepsilon_{2}=-\left(R m^{-1}+1\right)$ and $N=$ $\max \left[\alpha \varepsilon_{2}^{-1}+1, \beta \varepsilon_{2}^{-1}+e^{m(b-a)}, e^{m(b-a)}\right]$ is an underfunction of class $C^{2}[a, b]$. The following slightly stronger result can be proved: If $f\left(x, y, y^{\prime}\right)$ satisfies $A_{0}, A_{1}, A_{2}$, and if 


$$
\left|f\left(x, 0, y^{\prime}\right)-f(x, 0,0)\right| \leqq K\left[\left|y^{\prime}\right| \cdot \ln \left|y^{\prime}\right|+1\right]
$$

where $x \in[a, b]$ and $\left|y^{\prime}\right|<\infty$, then there exists an underfunction $\phi$ and an overfunction $\psi$ of class $C^{2}$ on $[a, b]$ with respect to the BVP (1.2).

The proof of this result follows by observing that any solution of $y^{\prime \prime}=K_{2} y^{\prime} l n y^{\prime}$ where $y(x) \geqq 0$ and $y^{\prime}(x) \geqq e$ on $[a, b]$ is a superfunction with respect to (1.1) provided $K_{2} \leqq-(2 K+M)$ where $M=$ $\max |f(x, 0,0)|$.

In general, one cannot replace (5.4) by the weaker condition:

$$
\left|f\left(x, 0, y^{\prime}\right)-f(x, 0,0)\right| \leqq K\left|y^{\prime}\right|^{1+v}
$$

where

$$
x \in[a, b], \quad\left|y^{\prime}\right|<\infty, \text { and } v>0 ;
$$

for consider the BVP:

$$
\begin{aligned}
y^{\prime \prime} & =1+\left(y^{\prime}\right)^{2} \\
y(0) & =0 \quad y(\pi / 2)=\beta \neq 0 .
\end{aligned}
$$

There exists no continuous underfunction on $[0, \pi / 2]$. However, if the length of the interval is suitably restricted, the following result holds.

THEOREM 5.3. Let $f\left(x, y, y^{\prime}\right)$ satisfy $A_{i}, i=0,1,2$, and (5.5), then, if $b-a<\left(v K_{1}\right)^{-1}$, there exists an overfunction $\psi(x)$ and an underfunction $\phi(x)$ of class $C^{2}[a, b]$ with respect to the $B V P(1.2)$.

Proof. Observe that any solution of the differential equation

$$
y^{\prime \prime}=-K_{1}\left(y^{\prime}\right)^{1+v}
$$

where $K_{1}=K+\max |f(x, 0,0)|, x \in[a, b]$, satisfying the conditions $y(x) \geqq 0$ and $y^{\prime}(x) \geqq 1$ on $[a, b]$ is a superfunction on $[a, b]$ with respect to (1.1).

If $v \neq 1$, the function $\psi(x)$ defined by

$$
\psi(x)=\left[K_{1}(v-1)\right]^{-1} \cdot\left(\left[v K_{1}(x-b)+1\right]^{(v-1) / v}-\left[v K_{1}(a-b)+1\right]^{(v-1) / v}\right)+\eta
$$

where $\eta=\max \left[\alpha, \beta+\left[K_{1}(v-1)\right]^{-1} \cdot\left[\left(v K_{1}(a-b)+1\right)^{(v-1) / v}-1\right], 0\right]$ is a solution of (5.6) and, if $b-a<\left(v K_{1}\right)^{-1}$, then $\psi(x) \geqq 0$ and $\psi^{\prime}(x) \geqq 1$ on $[a, b]$ with $\psi(a) \geqq \alpha$ and $\psi(b) \geqq \beta$. Thus, $\psi(x)$ is an overfunction of class $C^{2}[a, b]$ with respect to the BVP (1.2) for $v \neq 1$.

If $v=1$, the function

$$
\psi(x)=K_{1}^{-1} \ln \left|K_{1}(x-b)+1\right|+\eta
$$

where 


$$
\eta=\max \left[0, \alpha-K_{1}^{-1} \cdot \ln |K(a-b)+1|, \beta\right]
$$

is an overfunction of class $C^{2}[a, b]$, provided $b-a<\left(v K_{1}\right)^{-1}$.

An underfunction $\phi(x)$ can similarly be constructed.

6. Some existence theorems. Having found sufficient conditions which when imposed upon $f\left(x, y, y^{\prime}\right)$ imply assumptions $\mathrm{A}_{3}$ and $\mathrm{P}$, we proceed to state and prove some existence theorems for the BVP (1.2).

THeOREM 6.1. If $f\left(x, y, y^{\prime}\right)$ satisfies $A_{i}, i=0,1,2$, and if (6.1) $\left|f\left(x, 0, y^{\prime}\right)-f(x, 0,0)\right| \leqq K\left|y^{\prime}\right|$ where $x \in[a, b]$ and $\left|y^{\prime}\right|<\infty$, then $H(x)$, the generalized solution of the BVP (1.2), has a finite derivative at each point of $(a, b)$. In fact, $\left|H^{\prime}\left(x_{0}\right)\right| \leqq M$ where the constant $M$ depends on $x_{0}, a, b, \alpha, \beta, K$, and $R=\max |f(x, 0,0)|$ on $[a, b]$.

Proof. $H(x)$ exists on $[a, b]$. Let $x_{0} \in(a, b)$ and consider the two possible cases: (i) $H\left(x_{0}\right) \leqq 0$ and (ii) $H\left(x_{0}\right)>0$.

(i) Let $H\left(x_{0}\right) \leqq 0$. By the known properties of $H(x), H\left(x_{0}-0\right)$ and $H\left(x_{0}+0\right)$ exist and $H\left(x_{0}\right)=\min \left[H\left(x_{0}-0\right), H(x+0)\right]$. Assume without loss of generality that $H\left(x_{0}-0\right)=H\left(x_{0}\right)$. Any solution of

$$
y^{\prime \prime}=K_{1} y^{\prime}
$$

where $K_{1}=K+R$ with $y(x) \leqq 0$ and $y^{\prime}(x) \geqq 1$ is a subfunction by (3.5). Let

$$
A=\min \left[\phi(a), H\left(x_{0}\right)-\left(1-\exp \left[K_{1}\left(a-x_{0}\right)\right]\right)\left(K_{1} \exp \left[K_{1}\left(a-x_{0}\right)\right]\right)^{-1}\right],
$$

then the function $y_{1}(x)$ defined by

$$
\begin{aligned}
y_{1}(x)= & \frac{H\left(x_{0}\right)}{1-\exp \left[K_{1}\left(a-x_{0}\right)\right]}\left[\exp \left[K_{1}\left(x-x_{0}\right)\right]-\exp \left[K_{1}\left(a-x_{0}\right)\right]\right] \\
& +\frac{A}{1-\exp \left[K_{1}\left(a-x_{0}\right)\right]}\left[1-\exp \left[K_{1}\left(x-x_{0}\right)\right]\right]
\end{aligned}
$$

satisfies differential equation (6.2) with $y_{1}(a)=A, \quad y_{1}\left(x_{0}\right)=H\left(x_{0}\right)$, $y_{1}(x) \leqq 0$, and $y_{1}^{\prime}(x) \geqq 1$.

Since $y_{1}(x)$ is a subfunction of class $C^{2}$ on $\left[a, x_{0}\right]$ with $H(a) \geqq$ $y_{1}(a)$ and $H\left(x_{0}\right)=y_{1}\left(x_{0}\right)$, we assert that $y_{1}(x) \leqq H(x)$ on $\left[a, x_{0}\right]$. Assume not, then there exists an $x_{1} \in\left(a, x_{0}\right)$ such that $y_{1}\left(x_{1}\right)>H\left(x_{1}\right)$. Let $\varepsilon=y_{1}\left(x_{1}\right)-H\left(x_{1}\right)>0$, then $y_{1}(x)-\varepsilon / 2$ is a subfunction on $\left[a, x_{0}\right]$ by (3.8). By the definition of $H(x)$, there are continuous underfunctions $\phi_{1}$ and $\phi_{2}$ such that $H(a)-\phi_{1}(a) \leqq \varepsilon / 4$ and $H\left(x_{0}\right)-\phi_{2}\left(x_{0}\right) \leqq \varepsilon / 4$.

Define $\phi_{3}(x)=\max \left[\phi_{1}(x), \phi_{2}(x)\right]$ for $x \in[a, b]$, then $\phi_{3}(x)$ is a continu- 
ous underfunction on $[a, b]$ with $H(a)-\phi_{3}(a) \leqq \varepsilon / 4$ and $H\left(x_{0}\right)-\phi_{3}\left(x_{0}\right) \leqq$ $\varepsilon / 4$. Define $\phi^{*}$ on $[a, b]$ by:

$$
\phi^{*}(x)=\left\{\begin{array}{l}
\phi_{3}(x), \quad x \notin\left[a, x_{0}\right] \\
\max \left[\phi_{3}(x), y_{1}(x)-\varepsilon / 2\right], \quad x \in\left[a, x_{0}\right] .
\end{array}\right.
$$

$\phi^{*}(x)$ is a continuous underfunction by (3.6), but $\phi^{*}\left(x_{1}\right) \geqq y_{1}\left(x_{1}\right)-\varepsilon / 2=$ $H\left(x_{1}\right)+\varepsilon / 2$ which contradicts the definition of $H(x)$. Therefore, $y_{1}(x) \leqq H(x)$ for all $x \in\left[a, x_{0}\right]$.

Hence,

$$
\frac{H\left(x_{0}-0\right)-H(x)}{x_{0}-x} \leqq \frac{y_{1}\left(x_{0}\right)-y_{1}(x)}{x_{0}-x} \text { for } a \leqq x<x_{0}
$$

and

$$
\begin{gathered}
D H\left(x_{0}-0\right) \leqq y_{1}^{\prime}\left(x_{0}\right) \leqq K_{1}\left[1-\exp \left[K_{1}\left(a-x_{0}\right)\right]\right]^{-1} \cdot\left[H\left(x_{0}\right)-A\right] \\
\cdot \cdot \exp \left[K_{1} \max \left[b-x_{0}, x_{0}-a\right]\right] \\
=M_{1}\left(a, b, \alpha, \beta, x_{0}, K, R\right) .
\end{gathered}
$$

$D H\left(x_{0}-0\right)<M_{1}<+\infty$ implies, by (4.3), that $H\left(x_{0}-0\right) \geqq$ $H\left(x_{0}+0\right)$. Hence $H\left(x_{0}+0\right)=H\left(x_{0}-0\right)=H\left(x_{0}\right)$ and $H^{\prime}\left(x_{0}\right) \leqq M_{1}$.

By a similar argument applied to the right-hand side of $x_{0}$, there exists a constant $M_{2}$ depending on $a, b, \alpha, \beta, x_{0}, K$, and $R$ such that $M_{2} \leqq H^{\prime}\left(x_{0}\right)$.

Therefore,

$$
M_{2} \leqq H^{\prime}\left(x_{0}\right) \leqq M_{1}
$$

(ii) If $H\left(x_{0}\right)>0$, proof is similar to case (i) and will be omitted.

CoRollary 6.1. Under the hypotheses of Theorem 6.1, $H(x)$ is of class $C^{2}$ and a solution of (1.1) on $(a, b)$.

This follows from (4.1), (4.2), (4.3), and Theorem 6.1.

COROLLARY 6.2. If

(1) $f\left(x, y, y^{\prime}\right)$ satisfies $\mathrm{A}_{0}, \mathrm{~A}_{1}$, and $\mathrm{A}_{2}$,

(2) $f\left(x, y, y^{\prime}\right)=g\left(x, y, y^{\prime}\right)+h\left(x, y, y^{\prime}\right)$ on $T$,

(3) $h\left(x, 0, y^{\prime}\right)=0$ for $x \in[a, b]$ and $\left|y^{\prime}\right|<\infty$,

(4) $\left|g\left(x, 0, y^{\prime}\right)-g(x, 0,0)\right| \leqq K\left|y^{\prime}\right|$ for $x \in[a, b]$ and $\left|y^{\prime}\right|<\infty$, then $H(x)$ is of class $C^{2}$ and a solution of $(1.1)$ on $(a, b)$.

Our primary result is the following theorem.

THEOREM 6.2. If

(1) $f\left(x, y, y^{\prime}\right)$ satisfies $\mathrm{A}_{0}, \mathrm{~A}_{1}$, and $\mathrm{A}_{2}$, 
(2) there exists a positive continuous function $\phi(u)$ defined for $u \geqq 0$ such that

$$
\left|f\left(x, y, y^{\prime}\right)-f(x, y, 0)\right| \leqq K_{S} \phi\left(\left|y^{\prime}\right|\right)
$$

where $K_{S}$ is a constant depending on compact subsets $S$ of

$$
\{(x, y)|x \in[a, b],| y \mid<\infty\}, \quad(x, y) \in S, \quad\left|y^{\prime}\right|<\infty,
$$

and

$$
\int_{0}^{\infty} \frac{u d u}{\phi(u)+1}=+\infty
$$

(3) $\left|f\left(x, 0, y^{\prime}\right)-f(x, 0,0)\right| \leqq K\left|y^{\prime}\right|$ for $x \in[a, b]$ and $\left|y^{\prime}\right|<\infty$, then $H(x)$ is the solution of the BVP (1.2) of class $C^{2}[a, b]$.

Proof. By Theorems 4.1, 5.1, and 5.2, $H(x)$ is a solution of the BVP (1.2) in the sense defined. By standard arguments, $H(x)$ is in fact of class $C^{2}[a, b]$.

CoRollery 6.3. If

(1) $f\left(x, y, y^{\prime}\right)$ satisfies $\mathrm{A}_{0}$ and $\mathrm{A}_{1}$,

(2) $\left|f\left(x, y, y_{1}^{\prime}\right)-f\left(x, y, y_{2}^{\prime}\right)\right| \leqq K_{S}\left|y_{1}^{\prime}-y_{2}^{\prime}\right|$ where $K_{S}$ is a constant depending on compact subsets $S$ of $\{(x, y)|x \in[a, b]| y \mid,<\infty\},(x, y) \in S$, and $\left|y^{\prime}\right|<\infty$,

then $H(x)$ is the solution of the BVP (1.2) of class $C^{2}[a, b]$.

CoRollary 6.4. If

(1) $f\left(x, y, y^{\prime}\right)$ satisfies $\mathrm{A}_{0}$ and $\mathrm{A}_{1}$, and

(2) $\left|f\left(x, y, y_{1}^{\prime}\right)-f\left(x, y, y_{2}^{\prime}\right)\right| \leqq K\left|y_{1}^{\prime}-y_{2}^{\prime}\right|$ for all $\left(x, y, y_{1}^{\prime}\right),\left(x, y, y_{2}^{\prime}\right) \in T$, then $H(x)$ is the solution of the BVP (1.2) of class $C^{2}[a, b]$.

The above corollary was proven by Lees [4] using the method of finite differences.

If the Nagumo condition (Assumption 2 of Theorem 6.2) is dropped, it is still possible to assert the existence of the solution of BVP (1.2) provided some rather severe limitations are placed on the boundary values. with

THEOREM 6.3. If given the BVP: $y^{\prime \prime}=f\left(x, y, y^{\prime}\right), y(a)=0=y(b)$,

(1) $f\left(x, y, y^{\prime}\right)$ satisfying $\mathrm{A}_{0}, \mathrm{~A}_{1}, \mathrm{~A}_{2}$, and

(2) $\left|f\left(x, 0, y^{\prime}\right)-f(x, 0,0)\right| \leqq K\left|y^{\prime}\right|$ for all $x \in[a, b]$ and $\left|y^{\prime}\right|<\infty$, then $H(x)$ is the solution of the BVP (1.2). 
Proof. By Corollary 6.1, $H(x)$ is of class $C^{2}$ and a solution of (1.1) on $(a, b)$. Thus, it suffices to show, that under the additional stipulation of zero boundary values, $H(x)$ is continuous on $[a, b]$ and assumes the zero boundary values. This is accomplished by constructing an overfunction $\psi$ and an underfunction $\phi$ both of which are continuous on $[a, b]$ and such that $\phi(a)=\psi(a)=0$ and $\phi(b)=\psi(b)=0$.

Let $\phi_{1}(x)$ be a solution of

$$
y^{\prime \prime}=K_{1} y^{\prime}
$$

where $K_{1}=K+\max |f(x, 0,0)|$ for $x \in[a, b]$ satisfying the condition $\phi_{1}(x) \leqq 0, \phi_{1}^{\prime}(x) \geqq 1$, and $\phi_{1}(b)=0$, and let $\phi_{2}(x)$ be a solution of

$$
y^{\prime \prime}=-K_{1} y^{\prime}
$$

satisfying the conditions $\phi_{2}(x) \leqq 0, \phi_{2}^{\prime}(x) \leqq-1$, and $\phi_{2}(a)=0$, then $\phi_{1}(x)$ and $\phi_{2}(x)$ are subfunctions with respect to $(1.1)$ on $[a, b]$. Let $\phi(x)=\max \left[\phi_{1}(x), \phi_{2}(x)\right]$, then $\phi(x)$ is a continuous underfunction such that $\phi(a)=0=\phi(b)$.

Similarly, there exists a continuous overfunction $\psi(x)$ such that $\psi(a)=0=\psi(b)$.

Thus, $\phi(x) \leqq H(x) \leqq \psi(x)$ on $[a, b]$ and result follows.

COROLlaRY 6.5. If

(1) $g\left(x, y, y^{\prime}\right)$ satisfies $\mathrm{A}_{0}, \mathrm{~A}_{1}$, and $\mathrm{A}_{2}$,

(2) $g\left(x, 0, y^{\prime}\right)=0$ for all $a \leqq x \leqq b$ and $\left|y^{\prime}\right|<\infty$,

(3) $f\left(x, y, y^{\prime}\right)=h_{1}(x)+h_{2}(x) y^{\prime}+h_{3}(y)+g\left(x, y, y^{\prime}\right)$ where $h_{i}, i=$ $1,2,3$, are continuous on their respective domains and $h_{3}$ is nondecreasing,

then there exists a solution of the BVP: (1.1) with $y(a)=0=y(b)$.

\section{REFERENCES}

1. E. Coddington and N. Levinson, Theory of Ordinary Differential Equations, McGrawHill, New York, 1955.

2. N. Dunfold and J. Schwartz, Linear Operators, Part I: General Theory, Interscience, 1958.

3. L. Fountain and L. Jackson, A Generalized Solution for the Boundary Value Problem for $y^{\prime \prime}=f\left(x, y, y^{\prime}\right)$, Pacific J. Math., 12 (1962), 1251-1272.

4. M. Lees, A Boundary Value Problem for Nonliniar Ordinary Differential Equations, J. Math., Mech., 10 (1961), 423-430.

5. M. Nagumo, Über die Differentialgleichung $y^{\prime \prime}=f\left(x, y, y^{\prime}\right)$, Proc. Physics-Math. Soc. Japan, Series 3, 19 (1937), 861-866.

6. B. Picard, Leçons sur Quelques Problems aux Limites de la Theorie des Equations: Differentielles, Gauthier-Villars, Paris, 1930.

UNIVERSITY OF COLORADO 


\section{PACIFIC JOURNAL OF MATHEMATICS}

\section{EDITORS}

RalPh S. Phillips

Stanford University

Stanford, California

M. G. Arsove

University of Washington

Seattle 5 , Washington
J. Dugundu

University of Southern California

Los Angeles 7, California

Lowell J. Paige

University of California

Los Angeles 24, California

\section{ASSOCIATE EDITORS}
E. F. BECKENBACH
D. DERRY
H. L. ROYDEN
E. G. STRAUS
T. M. CHERRY
M. OHTSUKA
E. SPANIER
F. WOLF

\section{SUPPORTING INSTITUTIONS}

\author{
UNIVERSITY OF BRITISH COLUMBIA \\ CALIFORNIA INSTITUTE OF TECHNOLOGY \\ UNIVERSITY OF CALIFORNIA \\ MONTANA STATE UNIVERSITY \\ UNIVERSITY OF NEVADA \\ NEW MEXICO STATE UNIVERSITY \\ OREGON STATE UNIVERSITY \\ UNIVERSITY OF OREGON \\ OSAKA UNIVERSITY \\ UNIVERSITY OF SOUTHERN CALIFORNIA
}

\author{
STANFORD UNIVERSITY \\ UNIVERSITY OF TOKYO \\ UNIVERSITY OF UTAH \\ WASHINGTON STATE UNIVERSITY \\ UNIVERSITY OF WASHINGTON \\ AMERICAN MATHEMATICAL SOCIETY \\ CALIFORNIA RESEARCH CORPORATION \\ SPACE TECHNOLOGY LABORATORIES \\ NAVAL ORDNANCE TEST STATION
}

Mathematical papers intended for publication in the Pacific Journal of Mathematrcs should be typewritten (double spaced), and the author should keep a complete copy. Manuscripts may be sent to any one of the four editors. All other communications to the editors should be addressed to the managing editor, L. J. Paige at the University of California, Los Angeles 24, California.

50 reprints per author of each article are furnished free of charge; additional copses may be obtained at cost in multiples of 50 .

The Pacific Journal of Mathematics is published quarterly, in March, June, September, and December. Effective with Volume 13 the price per volume (4 numbers) is $\$ 18.00$; single issues, $\$ 5.00$. Special price for current issues to individual faculty members of supporting institutions and to individual members of the American Mathematical Society: $\$ 8.00$ per volume; single issues $\$ 2.50$. Back numbers are available.

Subscriptions, orders for back numbers, and changes of address should be sent to Pacific Journal of Mathematics, 103 Highland Boulevard, Berkeley 8, California.

Printed at Kokusai Bunken Insatsusha (International Academic Printing Co., Ltd.), No. 6 , 2-chome, Fujimi-cho, Chiyoda-ku, Tokyo, Japan.

\section{PUBLISHED BY PACIFIC JOURNAL OF MATHEMATICS, A NON-PROFIT CORPORATION}

The Supporting Institutions listed above contribute to the cost of publication of this Journal, but they are not owners or publishers and have no responsibility for its content or policies. 


\section{Pacific Journal of Mathematics}

\section{Vol. 13, No. $4 \quad$ June, 1963}

Dallas O. Banks, Bounds for eigenvalues and generalized convexity ........... 1031

Jerrold William Bebernes, A subfunction approach to a boundary value problem for

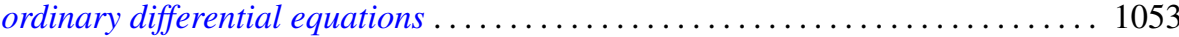

Woodrow Wilson Bledsoe and A. P. Morse, A topological measure construction . . . 1067

George Clements, Entropies of several sets of real valued functions . . . . . . . . . 1085

Sandra Barkdull Cleveland, Homomorphisms of non-commutative *-algebras . . . . . 1097

William John Andrew Culmer and William Ashton Harris, Convergent solutions of

ordinary linear homogeneous difference equations . . . . . . . . . . . . . . . 1111

Ralph DeMarr, Common fixed points for commuting contraction mappings . . . . . . 1139

James Robert Dorroh, Integral equations in normed abelian groups . . . . . . . . 1143

Adriano Mario Garsia, Entropy and singularity of infinite convolutions . . . . . . . 1159

J. J. Gergen, Francis G. Dressel and Wilbur Hallan Purcell, Jr., Convergence of extended Bernstein polynomials in the complex plane ................. 1171

Irving Leonard Glicksberg, A remark on analyticity of function algebras . . . . . . 1181

Charles John August Halberg, Jr., Semigroups of matrices defining linked operators

with different spectra ................................. 1187

Philip Hartman and Nelson Onuchic, On the asymptotic integration of ordinary

differential equations . . . . . . . . . . . . . . . . . . . . . . . . . . . . 1193

Isidore Heller, On a class of equivalent systems of linear inequalities . . . . . . . . . 1209

Joseph Hersch, The method of interior parallels applied to polygonal or multiply

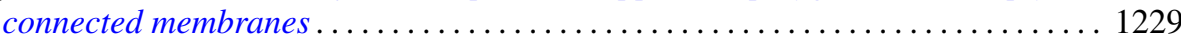

Hans F. Weinberger, An effectless cutting of a vibrating membrane . . . . . . . . . . 1239

Melvin F. Janowitz, Quantifiers and orthomodular lattices ....

Samuel Karlin and Albert Boris J. Novikoff, Generalized convex inequalities . .

Tilla Weinstein, Another conformal structure on immersed surfaces of negative

curvature.

Gregers Louis Krabbe, Spectral permanence of scalar operators

Shige Toshi Kuroda, Finite-dimensional perturbation and a representaion of

scattering operator.

Marvin David Marcus and Afton Herbert Cayford, Equality in certain

inequalities

Joseph Martin, A note on uncountably many disks .

Eugene Kay McLachlan, Extremal elements of the convex cone of semi-norms . . . . 1335

John W. Moon, An extension of Landau's theorem on tournaments . .

Louis Joel Mordell, On the integer solutions of $y(y+1)=x(x$

Kenneth Roy Mount, Some remarks on Fitting's invariants .....

Miroslav Novotný, Über Abbildungen von Mengen ............

Robert Dean Ryan, Conjugate functions in Orlicz spaces.

John Vincent Ryff, On the representation of doubly stochastic operators . . . . . . . . 1379

Donald Ray Sherbert, Banach algebras of Lipschitz functions .

James McLean Sloss, Reflection of biharmonic functions across analytic boundary

conditions with examples.

L. Bruce Treybig, Concerning homogeneity in totally ordered, connected topological space....

John Wermer, The space of real parts of a function algebra...

James Juei-Chin Yeh, Orthogonal developments of functionals and related theorems

in the Wiener space of functions of two variables......... 